the electrolysis of this double salt in the fused state, and from the oxide, by reduction with carbon in the electric furnace. All three processes give good yields, the last-mentioned being the best, if care be taken not to unduly prolong the heating in contact with carbon, and to exclude air.

Metallic uranium, when pure, is perfectly white, and is not magnetic if free from iron. It is not hard enough to scratch glass, takes a good polish, and can be filed with ease; in the electric forge it is much more volatile than iron.

M. Henri Becquerel, in the same number of the Comptes rendus, gives an account of a remarkable property of this metal, which appears to be unique, that of emitting in visible phosphorescent rays capable of producing photographic effects after travessing opaque bodies such as cardboard, aluminium, copper, and platinum, and also able to discharge a gold leaf electroscope. The effects produced are precisely similar to those previously obtained from uranium salts, such as potassium uranyl sulphate, except that they are nearly four times as intense. The chenical behaviour of uranium depends to a certain extent upon its state of division. The metal obtained by electrolysis, which is finely divided, takes fire in fluorine, is attacked by chlorine at $180^{\circ}$, by bromine at $210^{\circ}$, and by iodine at $260^{\circ}$, the reactions in all cases being complete. The powdered metal is completely burned in pure oxygen at $\mathrm{I}^{\circ} \mathrm{O}^{\circ}$, and decomposes water, siowly at the ordinary temperature but more quickly at $100^{\circ}$. Uranium must be added to the rapidly increasing group of metals which combine directly with nitrogen at high temperatures. Fragments of the metal heated to about $1000^{\circ}$ in a current of nitrogen become covered with a yellow layer of nitride, and hence in the preparation of the metal it is necessary to work in such a manner as to completely exclude air.

\section{SCIENCE IN THE MAGAZINES}

TIIE celebration of the Kelvin jubilee at Glasgow on June ${ }^{5}$ 17 , makes the appearance of an article on the renowned in vestigator, in the June number of Good Words, very opportune. The author is the editor, Dr. Donald Macleod, once a student of Lord Kelvin's, and his description of the master is a most appreciative one. Illustrations of Glasgow University, Lord Kelvin's class-room, laboratory, and study, and of Lord and Lady Kelvin, give additional interest to the article.

An excellent illustrated article on "The Rise of the Royal Society," is contributed to the Leisure Hour by Mr. Herbert Rix, the late Assistant Secretary of the Society. Other articles of scientific interest in the same magazine are "Notes on the Zoo," by Mr. W. J. Gordon, with illustrations from photographs by Mr. Gambier Bolton; "The New South Africa," by Mr. Basil Worsfold; and "Modern Hygiene in Practice," by Dr. A. T. Schofield.

Sience Gossip contains the first of a series of articles upon the scientific worthies at the National Portrait Gallery, illustrated with sketches of the pictures by Miss J. Hensman. We understand from the article that there are about thirty portraits of scientific men out of upwards of a thousand pictures in the Gailery.

An article on Africa since I888, with special reference to Sonth Africa and Abyssinia, by the Hon. Gardiner G. Hubbard, and accompanied by a striking portrait of the author, appears in the National Geographic Magazine (May). Another paper on Africa, "Impressions of South Africa," is contributed to the Century Magazine by Mr. James Bryce, M.P. In the Contemporary, there is an article by Dr. George Harley, F.R.S., on "Champagne," having medical as well as gustatory points of interest. Good Words has an article on "Aluminium," by Prof. Jamieson, and on "Flowers of the Forest," by Mr. Edward Step. Mr. W. H. Hudson has an article on "Ravens in Somersetshire" in Longman's Mayazine. Among the popular articles in Chambers's Journal is one on "Photography in Colours," descriptive of Mr. Ives' process, and another on the Harvey process for hardening steel. Sir Robert Ball describes the planet Saturn in the Strand Magasine. Student of animal life may be interested in the second paper on "The Evolution of the Trotting Horse," contributed by Mr. H. Busbey to Siribner.

In addition to the periodicals mentioned, we have received the Humanitarian, Fortnishtly, and the Sunday Magazine, but no articles in them call for notice here.

No. I 388 , voL. 54]

\section{UNIVERSITY AND EDUCATIONAL INTELLIGENCE.}

Mr. H. J. Heinty has given Io,000 dols. to the Kansas City University, the corner-stone of which has just been laid.

THE Technical Instruction Committee of the Middlesex County Council have decided to offer a scholarship, worth $£ 50$ per year for two years, tenable at the City and Guilds of London Institute. This scholarship is to be competed for by boys to whom scholarships at secondary schools were awarded in 1893 . It is to include school fees, railway fares, and maintenance.

THE following are among recent announcements:-Dr. Otto Fischer to be Extraordinary Professor of Mathematics in Leipzig University; Prof. L. M. Underwood to be called to the chair of Botany in Columbia University; Dr. George $A$ Dorsey to be Curator in the Department of Anthropology in the Field Columbian Museum at Chicago; Dr. Franz Boas to be Lecturer on Physical Anthropology in Columbia Unirersity; Prof. Harold B. Smith to be Professor of Electrical Engineering in the Worcester Polytechnic Institute.

For news of the following gifts to education and research in America, we are indebted to Sicence:-Mr. Thomas McKean has offered to give 100,000 dols. to the University of Pennsylvania upon condition that $\mathrm{I}, 000,000$ dols. be collected. Mr. McKean, who is a trustee and an alumnus of the University, gave 50,000 dols. about a year ago.---Mr. Charles M. Dalton has given the Massachusetts Institute of Technology 5000 dols. for a scholarship in chemistry for graduate students. Preference will be given to those undertaking chemical research applicable to textile fabrics.-Real estate and securities valued at 2 15,000 dols. have been presented to the North-western University by William Deering, of Evanston, who had previously given the University about 200,000 dols.

WE have to record another attempt to divert part of the funds available under the Local Taxation (Customs and Excise) Act. I890, to the General County Fund. This time it is the Isle of Ely County Council. At their meeting held at March, on May 20 , it was proposed " that $£ 1000$ of the Imperial grant be allocated to the General County Fund, instead of the $f \mathrm{I} 50$ recommended by the Committee." The proposal was eventually rejected, it is true, but only by a majority of two in a meeting of forty. The argument which was used in the North Riding County Council a short time ago, and to which we called attention, was again repeated-that it was never the intention of Parliament for the whole of these funds to be devoted to the purposes of technical education. No stronger reason than such occurrences as these could be found for the necessity of the provision in the Elucation Bill that these funds must be devoted to educational purposes.

WE are glad to learn from Science that an effort is now under way in connection with the National Educational Association to bring about greater interest in the teaching of science than has hitherto been shown by American botanists, zoologists, chemists, physicists, \&c. The new Department of Natural Science In struction is intended to bring together the teachers of the natural sciences who are interested in science as a means of culture, and to stimulate thought and discussion as to how this end may best be obtained. What róle should botany, zoology, chemistry, physics, \&c., play in the mental development of man? In what way may the study of plants, animals, chemical compounds and physical forces be made an efficient factor in a man's mental training? When and how shall such study be made a part of a man's training? These are some of the questions which will be discussed in the Department of Natural Science Instruction in the Buffalo meeting of the National Educational Association, on Thursday and Friday afternoons (July 9 and Io).

THE Technical Instruction Committees of the Oxfordshire County Council have decided to devote $£ 560$ to scholarships during the next year. Of this amount $£ 294$ will be absorbed on account of the scholars already elected. The balance is to be devoted to further developing the scholarship scheme. Amongst other arrangements, we notice that it is proposed to elect three sons of tenant farmers to County Council scholarships of an annual value of $f \mathrm{I}_{5}$. The candidates must have been under fourteen years of age on December 3I, I895, and must have lived in the county for two years previously. The scholarships will be held at Burford Grammar School for the first two years. Sums of $£ 366$ and $£ 314$ have been respectively allotted for capitation 
grants and rural agricultural instruction. The programme for the year also makes the following provisions :-For dairy instruction, $£ 250$; for manual instruction in woodwork, $£ 228$; for nursing, ambulance, and general hygiene, $£ 190$; for dressmaking, $£$ Ioo; for instruction in poultry-keeping, $£ 35$; for hedging and thatch ing, $£ 25$. We are very sceptical as to the wisdom of so diffuse a syllabus of work, and would again point out that no efforts should be spared to coordinate and systematise all the educational projects of a County Committee.

A prospectus referring to the Faculty of Applied Science of McGill University, Montreal, announces that, through the munificence of Mr. W. C. McDonald, a Department of Architecture has been established in the Faculty, and the regular work of the new department will commence with session 1896-97. During the summer, a Professor of Architecture is to be appointed, and the efficiency of the Drawing Department is to be much increased by the addition of a lecturer in freehand drawing and descriptive geometry. The same benefactor has also rendered it possible for the University to place the Departments of Chemistry and Mining in a thoroughly efficient condition. The erection of a large building is to be proceeded with immediately, and the building will be equipped in the most approved manner, including not only provision for the several branches of chemistry, but also for mineralogy, mining, and metallurgy. The Mining and Metallurgical Laboratories alone will have a floor space of about I0,000 square feet, and will be supplied with the most recent appliances for the milling and metallurgical treatment of ores, \&c. A Professor of Mining will be appointed during the summer, and other important changes in the staff, all leading to increased efficiency, are to be made.

\section{SCIENTIFIC SERIALS.}

Symons's Monthly Meteorological Magazine, May. - The worst gale of the nineteenth century in the English midlands. This storm occurred on March 24, I895, and has not been fully discussed, although some local scientific societies have published short papers upon it. The present number contains part of the list of damage done in various countries; in the next number it is proposed to complete it, and to offer some general remarks upon the subject. Mr. Symons considers that the damage done is without parallel since "the great storm" of 1703 . It is a curious coincidence that it occurred on the same day of the year, and nearly at the same hour, as that of the Eurydice squall in 1878 , in which, it will be remembered, Her Majesty's ship was lost. This latter storm was discussed by the late Mr. W. C. Ley. - Fog, mist, and haze, by "F. R. Met. Soc." In the hope of initiating a discussion upon the existing absence of unanimity as to the meaning attached to the different words in general use, the author has suggested certain definitions, which are briefly as follows: $-\mathrm{Fog}$; an obscuration due to condensation of aqueous vapour when the particles are too small to be seen with the naked eye. Mist; when the particles are large enough to be seen with the naked eye. Smoke-fog; obscuration without water particles. Haze; an obscuration of distant objects, so slight that the cause is not visible to the observer.

\section{SOCIETIES AND ACADEMIES. LONDON.}

Chemical Society, May 7.-Mr. A. G. V. Harcourt, President, in the chair.-The following papers were read:Carbon dioxide, its volumetric determination, by W. H. Symonds and F. R. Stephens. The authors describe a trustworthy method of estimating carbon dioxide in air. - On certain views concerning the condition of the dissolved substance in solutions of sodium sulphate, by R. F. D'Arcy. Experiments on the viscosity of strong solutions of sodium sulphate confirm the generally accepted view that the condition of sodium sulphate in aqueous solution is always the same, whether the solutions are prepared from the anhydrous salt or one of its two hydrates. - Luteolin, II., by A. G. Perkin. The results of the further examination of luteolin are given; it is isomeric with fisetin, and probably has the constitution $\mathrm{C}(\mathrm{OH}), \mathrm{CH}: \mathrm{C} \cdot \mathrm{CO}-\mathrm{C}_{\mathrm{C}} \mathrm{C}_{6} \mathrm{H}_{3}(\mathrm{OH})^{2}$

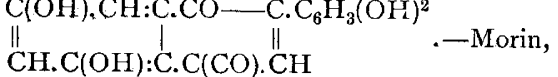

Part I., by H. Bablich and A. G. Perkin. Morin, a yellow colouring matter occurring in old fustic and in Jackwood, is isomeric with, and has a very similar constitution to quercitin.-Synthesis of pentacarbon rings. Part I. Anhydracetonebenzil and its homologues, by F. R. Japp and G. D. Lander. Anhydracetone benzil has been fully investigated, and is shown to be a diphenyl. hydroxycyclopentane of the constitution $\mathrm{CPh}=\mathrm{CH}$

$\mathrm{CPh}(\mathrm{OH}) . \mathrm{CH}_{2}$
Synthesis of pentacarbon rings with acetonedicarboxylic acid, by F. R. Japp and G. D. Lander. The behaviour towards reagents of anhydracetonebenzilcarboxylic acid, which is obtained by the condensation of benzil with acetonedicarboxylic acid, is described.-Reduction of desylene acetic acid, and the constitution of Zinin's pyroamaric acid, by F. R. Japp and G. D. Lander. Desyleneacetic acid yield. Meyer and Oelker's desylacetic acid on reduction and $\beta \gamma$ diphenylbutyric acid on boiling with hydriodic acid and phos phorus ; this acid is identical with Zinin's pyroamaric acid.-Electrolysis of potassium allo-ethylic camphorate, by J. Walker and J. Henderson.-Flourene and acenapthene, by W. R. Hodgkinson. The red substance obtained by the oxidation of flourene and acenaphthene is not a hydrocarbon, but contains oxygen; no coloured hydrocarbon can be prepared by oxidising these substances.

Mathematical Society, May I4.--Major MacMahon, R. A., F.R.S., President, in the chair.-Mr. H. F. Baker spoke upon the bitangents of a plane quartic curve and the straight lines of a cubic surface.-A paper by Prof. E. W. Brown, on the application of the principal function to the solution of Delaunay's canonical system of equations, was taken as read.-Short communications were made by the President, Colonel Cunningham, Prof. Hill, F. R.S., Mr. Hammond, and Mr. Tucker.

\section{CAMBRIDGe,}

Philosophical Society, May I I.--Prof. J. J. Thomson, President, in the chair. - Note on the formation of the layer in Amphioxus, by Mr. E. W. MacBride.-Note on the continuity of the mesenchyme cells in Echinoderms, by $\mathrm{Mr}$. E. W. MacBride. - Mr. F. C. Shrubsall read a paper on crania from Teneriffe, embodying the measurements of sixty-one skulls and two hundred long bones. The average height of the islanders, calculated from the latter, was for males $\mathrm{I} 642 \mathrm{~mm}$. and for females $155^{2} \mathrm{~mm}$.

\section{EDINBURGH.}

Royal Society, May I8. - Prof. Chrystal in the chair.-Mr. W. G. Robson, St. Andrews, exhibited some X-ray phutographs, and described the progress of the study at St. Andrews University. Some of the exposures were long compared with what has been done recently, notably by Dr. Macintyre; but the photographs were all very good, and the definitions rem urkably clear. Some of the pictures shown were very interesting. A photo of a mummy's foot was exhibited, and Mr. Robson remarked that the rays must have had some effect on the skin, for, at the end of the experiment, it was found to be quite soft. A photograph of what looked at first sight like some insect, but turned out to be a St. Andrews "bulger" with the lead showing very clearly, caused some amusement. Prof. Chrystal thought that uranium would be of great use in intensifying X-ray photo graphs. - Prof. D'Arcy Thompson made a short preliminary com. munication on the bird and beast names in Albertus Magnus. There were very many barbarous-looking names for beasts and birds in Albertus Magnus, which have a certain resemblance to words in Aristotle. The Dominican friar did not know Greek, but used an Arabic translation of Aristotle. If the Greek words were transliterated into Arabic, they were found to be parallel with the words used by Albertus when treated in the same way.- - Prof. Thompson also read a paper on the $\mathbf{\Sigma}$ of Diophantus. Diophantus used $\mathbf{\Sigma}$ for an unknown quantity. Most commentators take this to be the $s$ of $\dot{\alpha} \rho t \theta \mu \alpha s^{\prime}$ (" $\delta \dot{\alpha} \alpha \rho \iota \sigma \tau o s$ a $\rho\left(\theta \mu \delta s^{\prime}\right.$ "), but there are difficulties attached to this interpretation. Sometimes the $\Sigma$ has the sign of the genitive or plural written in small letters beside it, pointing rather to the fact of its being an initial letter. Prof. Thompson suggested $\sigma \omega \rho$ ós, a heap, connected with the heap-calculus of the Egyptians, and gave various reasons for his suggestion. If true, this hypothesis, in linking Diophantus on to the Eastern culture, deprived him of his position as the father of mathematics, and helped to prove that many of his problems, as was conjectured long ago by Morgan and Bonnycastle, were not original but were collected from NO. I388, vOL. 54] 